\title{
Eating Breakfast or Attending Extracurricular Tutoring, Which One is More Effective in Improving Student's Performance? An Empirical Study Based on the Data from A Large-Scale Provincial Survey
}

\author{
Yanli Liu, ${ }^{1}$ Jijun Yao, ${ }^{1}$ Wenye Li, ${ }^{1}$ Ru Cai, ${ }^{1}$ Shike Zhou ${ }^{2}$ \\ 1. Nanjing Normal University, Nanjing 210024, China \\ 2. Jiangsu Teaching and Research Office of Primary and Secondary \\ Schools, Nanjing 210024, China
}

\begin{abstract}
To improve children's academic achievements, parents often try to provide them with adequate nutrition or/and send them to attend extracurricular tutoring classes. The effect of extracurricular tutoring on students' performance has been well explored, whereas no rigorous empirical study was conducted to observe the relationship between breakfast and students' academic performance. Besides, little empirical evidence has been presented to compare the effect of breakfast and that of extracurricular tutoring on students' academic achievements. This study fills this gap by adopting the multiple linear regression model and Shapley Value Decomposition to analyze the academic quality monitoring data of 50,516 Year-3 students and 83,505 Year-8 students in Jiangsu, China. The results showed that both breakfast and extracurricular tutoring can improve students' grades, and breakfast was superior to the tutoring in efficacy. This conclusion is of great significance for planning family education strategies scientifically and improving family education efficiently. It is necessarily convincible for parents and educators to rationally understand the role of extracurricular tutoring and pay enough attention to breakfast in improving students' performance.
\end{abstract}

Sci Insigt Edu Front 2020; 5(1):481-499.

Doi: 10.15354/sief.20.ar029

Keywords: Breakfast; Extracurricular Tutoring; Student Achievements;

Family Education; Shapley Value Decomposition 


\section{Background}

$\mathrm{T}$

WHE scarcity of quality education and the fierce competition for advanced education in China force a large number of Chinese parents to send their children to various extracurricular tutoring classes. However, existing studies have not reached a consensus on whether attending extracurricular classes can improve students' academic performance or not. Instead, three different types of findings have been reported: (1) Extracurricular tutoring is beneficial for students' learning (Fang \& Xue, 2014; Peng \& Zhou, 2008); (2) Extracurricular tutoring is useless (Li, 2018; Liu \& Wang, 2018; Tang \& Fu, 2007); (3) The effectiveness of the extracurricular tutoring may vary depending on the length of the tutorial, the group of the student, gender and subject (Hu et al.2015; Li et al., 2016; Sun \& Tang,2019; Xue et al.,2014; Xue \& Ding 2009; Zhang,2013). Meanwhile, issues caused by extracurricular tutoring have also been explored. Such as extracurricular tutoring increased students' workload, decreased their independence and autonomy, and even caused weariness and antagonistic psychology (Wang, 2005; Yang, 2004). Furthermore, urban students and students with high socio-economic background having more chance to get extracurricular tutoring, this becomes an inter-generational transmission channel of family's social, economic, cultural and political capital (Xue, 2017) and also becomes another kind of social reproduction mechanism in addition to regular school education (Xue, 2016).

Besides good educational resources, providing children with enough nutrition is another important function of family education. In comparison with lunch and dinner, breakfast is more important for teenagers' physical and mental health, in that it serves as a nutritional supplement after a long interval of eating. It has been found that breakfast affected adolescents' psychology (O'Sullivan et al., 2009) and it had positive short-

About the Authors: Yanli Liu, School of Education Science, Nanjing Normal University, Nanjing 210024, China, Email: 1609604712@qq.com;

Wenye Li, School of Education Science, Nanjing Normal University, Nanjing 210024, China, Email: 841659607@qq.com;

Ru Cai, School of Education Science, Nanjing Normal University, Nanjing 210024, China, Email: 924654819@qq.com;

Shike Zhou, Jiangsu Teaching and Research Office of Primary and Secondary Schools, Nanjing 210024, China, Email: jyszsk@163.com.

Correspondence to: Jijun Yao, School of Education Science, Nanjing Normal University, Nanjing 210024, China, Email: yaojijun_njnu@163.com.

Funding: The study was funded by the Priority Academic Program for Development of Jiangsu Higher Education Institutions (PAPD).

Conflict of Interests: None. 
term effect on students' cognitive functions (e.g. attention, vocabulary and spatial memory) and emotional functions like alertness (Widenhorn-Muller et al., 2008). Breakfast can produce higher energy and satiety, lower fatigue and less hunger, and higher blood sugar level (Cooper et al., 2011). On the other hand, failure to eat breakfast regularly may lead to poor nutrition condition, a big possibility of obesity, higher blood pressure, and metabolic syndrome (Ho et al., 2015; Rampersaud et al., 2005) and a higher level of stress including anxiety and depression (Lien, 2007). Some studies investigated the relationship between breakfast and students' academic performance and cognitive development and a positive effect was found of breakfast on students' academic performance (Kang \& Park, 2016; Sampasa-Kanyinga \& Hamilton, 2017; Sun \& Yin, 1994; Xu et al., 2014). Specifically, a systematic review of school feeding programs implemented by the International Initiative for Impact Evaluation (3iE) in East and South Asia found that school feeding programs improved student learning outcomes (Snilstveit, et al., 2015). In addition, American School Breakfast Program (SBP) found that SBP significantly improved students' mathematics scores in large academic tests (Frisvold, 2015). When it was compared with many other factors like socioeconomic background and location, breakfast has a greater positive effect on students' academic achievement (Fang, 2018).

Since both breakfast and extracurricular tutoring are the most commonly used interventional measures for improving students' academic performance in family education, the aforementioned studies are of great significance in guiding parents' choices in family education. However, given the limitations of previous data and research methods, our understanding regarding the precise effect of breakfast and extracurricular tutoring is not sufficient yet. For instance, the published researches on breakfast had mostly been conducted in the field of medicine and public health, of which mainly focused on exploring the breakfast habits and their potential influencing factors. Besides, research on breakfast's role in students' cognitive development is relatively deficient. Although a few studies have compared the effectiveness of breakfast and that of tutoring on children's academic achievements, they did not demonstrate their inter-relationship. For example, Hau (2016) published an article "Have breakfast rather than wasting money on tutorials", in which the benefits of breakfast were analyzed, but it remained unclear whether the effect of breakfast was actually greater than that of the extracurricular tutoring. According to a news report, Jian Liu, chief expert of the China's Education Quality Monitoring Center and director of the China Education Innovation Research Institute at Beijing Normal University, made a comprehensive evaluation of the quality of basic education (Year-1 to Year-9) in Zhejiang Province in 2016 and stated that "Weekend tutorial is not as good as having breakfast every day" (Zhejing, 2017). However, no strong statistic evidence was presented to support the opinion.

Thus, we firstly used large-scale testing and survey data from the monitoring of the academic quality of students in basic education in Jiangsu Province to study the potential role of breakfast in students' cognitive development. Our finding indicated that regularly eating breakfast significantly promoted students' cognitive development (Yao et al., 2019). Based on this finding, we move on to question between eating breakfast 
and attending tutoring, which one is more effective in improving students' performance? In this study, breakfast and extracurricular tutoring were selected as the main independent variables and students' academic performance was selected as the dependent variable. A multiple linear regression model was established to analyze the relationship between breakfast, extracurricular tutoring and academic performance under the control of the confounding factors, such as family background and school type. In order to determine which factors are more effective, Shapely Value Decomposition method was used to calculate the relative contribution rate of each influencing factor to the difference in students' performance. The result not only proves the hypothesis, but also provides solid evidence of how to improve students' academic performance more effectively in family education.

\section{Data}

The data of this study derived from the monitoring data of academic quality of basic education (Year-1 to Year-9) students in Jiangsu Province in 2018. Specifically, the data was derived from a two-stage stratified sampling survey conducted to gather information on the academic performance (Chinese Language, Mathematics) of Year-3 and the academic performance (Chinese Language, Mathematics, English Language, Geography, Biology and Physics) of Year-8 students in Jiangsu Province. The test papers are prepared by the experienced Committee of Experts of the Jiangsu Province Basic Education Quality Monitoring Center. One year after Setting Questions, Tests, Interviews, and Adjustments to determine the final official and standby papers. To test the level of the students' basic knowledge, basic skills and the accomplishment in collecting and dealing with information, analyzing and solving problems, and so on. The test has higher reliability and validity. A total of 101,673 Year-3 students and 117,010 Year-8 students were sampled in this survey in 2018. In addition, the monitoring data also include the questionnaire of students, teachers and principals, among which student questionnaires were selected to obtain the data needed in this study. Prior to the analysis, the data were processed to eliminate samples with missing values and incorrectly filled key variables. Finally, 50,516 and 83,505 student samples were included in the analysis at the elementary and middle school stages, respectively. Furthermore, we analyzed the remaining data to confirm that the distribution and characteristics of the remaining samples were not significantly different from the sample, from which we found that processing the data did not cause a systematic difference.

It should be noted acknowledged that part of the data we used in this study partially overlapped with our previously reported data (Yao, et al., 2019) which belongs to different research branches of one big project. Therefore, in the process of data analysis, while respecting the copyright of the previously published data, we hereby make a special statement on the reuse of these data. The partially overlapping data can be found in the journal of Medical Science Monitor (Yao, et al., 2019).

However, there are differences in the sample scope between this current study and the previously published study. The main reason is that one of the main variables of 
this study, extracurricular tutoring, includes incorrectly filled samples in the questionnaire. So a difference appeared in the sample size when we removed these incorrectly filled samples. Specifically, in the original questionnaire, there are two questions (\#18 and \#20) that reflect whether or not students participated in extracurricular tutoring at the same time. We, in this study, eliminated the samples in which the questions were incorrectly answered. For example, a student selected the option that showed he or she took part in extracurricular tutoring in question \#18 but chose 0 as the length of tutoring in question \#20 or chose not participated in extracurricular tutoring in question \#18, but neither did choose 0 as the length of tutoring in question \#20, so this kind of sample was eliminated.

\section{Variables}

The core explanatory variables are breakfast and extracurricular tutoring. Breakfast was measured by two indices. One index was "whether do you eat breakfast or not", which served to estimate the influence of students' breakfast habit on their grades. Students who ate breakfast every day for a week was valued by 1 and in the case of irregular breakfast, the value was 0 . The other index was breakfast frequency, which shows the number of days a student ate breakfast within a week to estimate the impact of breakfast intake on their grades.

Extracurricular tutoring, also known as extracurricular learning and shadowing education, is also an important explanatory variable in this study. The definition and measurement methods were not completely consistent with the previously reported studies (Mark \& Liu, 2015). We here defined extracurricular tutoring as remedial activities that students receive outside formal school education, which mainly includes two forms of tutoring - tutorial class and home tutor. A total of five levels were set to represent different lengths of a weekly tutorial, with 1 indicating that not participating in any extracurricular tutoring; 2 meaning that the duration of the extracurricular tutoring was less than 3 hours; 3 showing that the duration was between 3 to 6 hours; 4 depicting that the duration was between 6 to 8 hours; and 5 meaning that the tutorial lasted for more than 8 hours.

The explained variable is the standardized student scores. The mean scores of students' participating subjects were substituted into the analytical model. Based on the previous studies (Xue, 2016), the control variables in this study involved three layers, which were individual, family and school layers. Among them, individual variables included students' genders and whether or not they had any siblings. The family variables include families' socioeconomic statuses, which were presented as the family socioeconomic status index calculated from family economic status, parents' education degree and occupation. The family economic status was synthesized by Rasch Model into a numerical calculation with the data of household gathered from the questionnaire. The degree of education of parents was expressed with the total number of years of education. Specifically, middle school or below, high school, college or graduate school were defined as 9, 12, 16 and 19 years, respectively. The professional prestige for parents 
mainly refers to the research of $\mathrm{Li}$ (2005) and $\mathrm{Lu}$ (2002). Meanwhile, the socioeconomic status of the family was calculated in the following way. First, to ensure the comparability, the "relative comparison" method was used (Yao, 2008) to standardize the index data:

$$
\text { The Standardized Data of An Index }=\frac{\text { The Original Value }- \text { The Minimum Value }}{\text { The Maximum Value }- \text { The Minimum Value }}
$$

Second, we used the Principal Component Analysis (PCA) to calculate the weight of each index. The standardized index was multiplied by corresponding weight. Finally, the socioeconomic status index of the family was obtained. The equation is as follows:

Family's socioeconomic status index=family economic status $* 0.24+$ father's education level $* 0.155+$ mother's education level $* 0.168+$ father's occupation $* 0.186+$ mother's occupation $* 0.251$.

The final result in family socioeconomic status was converted into value between 0 and 100. Variables at the school level include urban and rural categories. Besides, considering the differences of social and economic development in the North, Central and South of Jiangsu Province, we also substituted the region where the schools were located as a control variable.

\section{Results and Discussion}

\section{Descriptive Statistics}

The statistical description of elementary school variables (Table 1) shows that $89.7 \%$ of the elementary school students ate breakfast every day and most of them spent about three hours per week on extracurricular tutoring. Besides, $46.1 \%$ of the students had no siblings. The proportion of boys in the elementary school sample was larger than that of girls, and the sampling schools were mainly public schools locating in the southern part of Jiangsu Province.

The statistical description of variables in middle school (Table 2) depicts that $71.6 \%$ of the middle school students ate breakfast every day. The percentage was smaller than that of the elementary school students. However, similar to elementary school students, most of the middle school students spent about three hours on extracurricular tutoring each week. Besides, 51.4\% of these students had no siblings. Furthermore, the proportion of male students in the middle school sample was larger than that of female students.

\section{The Analysis of Effects between Breakfast, Extracurricular Tutoring and Students' Academic Performance}


Table 1. Sample Characteristics (Elementary School).

\begin{tabular}{llllll}
\hline & Variables & Mean & SD & Min & Max \\
\hline $\begin{array}{l}\text { Dependent } \\
\text { Variable }\end{array}$ & Students' academic performance & 525.513 & 79.709 & 193.897 & 719.251 \\
\hline \multirow{2}{*}{$\begin{array}{l}\text { Independent } \\
\text { Variables }\end{array}$} & Eat breakfast & 0.897 & 0.304 & 0 & 1 \\
\cline { 2 - 6 } & Breakfast frequency & 6.774 & 0.800 & 1 & 7 \\
\cline { 2 - 6 } & Time of extracurricular tutoring & 2.267 & 1.251 & 1 & 5 \\
\hline & $\begin{array}{l}\text { Family socioeconomic status in- } \\
\text { dex }\end{array}$ & 58.579 & 20.704 & 0 & 100 \\
\cline { 2 - 6 } & $\begin{array}{l}\text { Only child (Non-only children } \\
\text { were the control group) }\end{array}$ & 0.461 & 0.498 & 0 & 1 \\
\cline { 2 - 6 } & $\begin{array}{l}\text { Gender (Girls were the control } \\
\text { group) }\end{array}$ & 0.538 & 0.499 & 0 & 1 \\
\cline { 2 - 6 } & & &
\end{tabular}

Urban and rural categories schools belong to

(Rural schools were the control group)

\section{Control Variables}

\begin{tabular}{lllll}
\hline City & 0.729 & 0.445 & 0 & 1 \\
\hline Country town & 0.219 & 0.414 & 0 & 1 \\
\hline $\begin{array}{l}\text { Regions schools belong to } \\
\text { (Northern Jiangsu were the control group) }\end{array}$ & & & \\
\hline Central Jiangsu & 0.104 & 0.305 & 0 & 1 \\
\hline Southern Jiangsu & 0.665 & 0.472 & 0 & 1 \\
\hline
\end{tabular}

The type of school

(Private schools were the control group)

\begin{tabular}{lllll}
\hline Public school & 0.935 & 0.247 & 0 & 1
\end{tabular}

Note: Due to this research is a different branch of the same project, there is some data overlap. Most of the data in this table are basically consistent with the data of the project team's previous research paper (Yao, et al., 2019). The slight difference is the difference in sample size.

To figure out the influence of breakfast and extracurricular tutoring on students' academic performance, we established five models to explore the relationship between breakfast, extracurricular tutoring and students' performance.

$$
\begin{aligned}
& \text { Score }_{i}=\alpha+\alpha_{1} B_{i}+\alpha_{i} Z_{i}+\varepsilon_{i} \\
& \text { Score }_{i}=\beta+\beta_{1} \text { BrFrequency }_{i}+\beta_{i} Z_{i}+\varepsilon_{i} \\
& \text { Score }_{i}=\delta+\delta_{1} \text { TimeofTutoring }_{i}+\delta_{i} Z_{i}+\varepsilon_{i} \\
& \text { Score }_{i}=\lambda+\lambda_{1} B_{i}+\lambda_{2} \text { TimeofTutoring }_{i}+\lambda_{i} Z_{i}+\varepsilon_{i} \\
& \text { Score }_{i}=\omega+\omega_{1} \text { BrFrequency }_{i}+\omega_{2} \text { TimeofTutoring }_{i}+\omega_{i} Z_{i}+\varepsilon_{i}
\end{aligned}
$$


Where, Score $_{i}$ represents the academic performance of student ${ }_{i}$ and $B_{i}$ represents whether student $t_{i}$ eats breakfast regularly. If student $t_{i}$ eats breakfast every day for a week, the value is 1 ; if student $t_{i}$ eat breakfast irregular for a week, the value is 0 . Meanwhile, BrFrequency $y_{i}$ is the frequency of student's weekly breakfast intake,

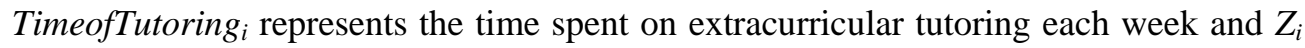
is the control variable, which includes gender, having siblings or not, family background, school area and school type. $\varepsilon_{i}$ represents the random error.

The collinearity of the independent variables in each regression model was tested and the results showed that the variance inflation factor VIF of all the independent variables was less than 10, indicating that there was no severe collinearity between the variables in the regression equation. The results of White test showed that the null hypothesis of model (1)-model (5) was reject at the significance level of $1 \%$, so the regression model had heteroscedasticity (see Table 3 for the detailed results), leading to the estimated results obtained by the regression model biased. The main methods to deal with heteroscedasticity include regression using Weighted Least Square method (WLS) (Wooldridge, 2009). Therefore, in this study, WLS was adopted to modify the heteroscedasticity. The revised regression results of elementary school sample and middle school sample are shown in Tables $\mathbf{4}$ and $\mathbf{5}$, respectively.

The analysis results in Table 4 illustrate that after the individual, family and school characteristics were controlled, breakfast and extracurricular tutoring were significantly positively correlated with the elementary students' academic performance, both of which were at the significance level of $1 \%$. According to the results of models (1) and (4), students who ate breakfast every day scored about 30 points higher than those who ate breakfast irregularly during the week. Besides, models (2) and (5) demonstrated that after the other factors affecting students' academic performance were controlled, performance would be improved by about 14 points for every additional day of breakfast in a week. The results of models (3), (4) and (5) depict that, after the other variables were controlled, extracurricular tutoring had a significant positive impact on the academic performance.

Table 4 also illustrates that the socioeconomic status index of the family has a significant positive influence on elementary students' academic performance, indicating that the students with better family background tended to get higher scores. In terms of individual characteristics of students, the scores of the female students were higher than those of the male peers, and the scores of the students without sibling were higher than those with siblings. As for school characteristics, the scores of the urban students were higher than those from the rural area, whereas the scores of the students from counties or towns were lower than those of the rural students. Furthermore, the scores of the students in the Central and Southern parts of Jiangsu were higher than those in the Northern part of Jiangsu. The students' academic grades from public school were less than those of their peers from private schools by 3-4 points.

The statistics in Table 5 shows that the results of the middle school sample are basically consistent with those of the elementary school sample. After students' individual characteristics were controlled, family background characteristics, school charac- 
Table 2. Sample Characteristics (Middle School).

\begin{tabular}{|c|c|c|c|c|c|}
\hline & Variables & Mean & SD & Min & Max \\
\hline $\begin{array}{l}\text { Dependent } \\
\text { Variable }\end{array}$ & Students' academic performance & 508.812 & 87.661 & 147.151 & 783.572 \\
\hline \multirow{3}{*}{$\begin{array}{l}\text { Independent } \\
\text { Variables }\end{array}$} & Eat breakfast & 0.716 & 0.451 & 0 & 1 \\
\hline & Breakfast frequency & 6.356 & 1.274 & 1 & 7 \\
\hline & Time of extracurricular tutoring & 2.112 & 1.328 & 1 & 5 \\
\hline \multirow{11}{*}{$\begin{array}{l}\text { Control } \\
\text { Variables }\end{array}$} & $\begin{array}{l}\text { Family socioeconomic status in- } \\
\text { dex }\end{array}$ & 48.925 & 18.684 & 0 & 100 \\
\hline & $\begin{array}{l}\text { only child (Non-only children were } \\
\text { the control group) }\end{array}$ & 0.514 & 0.5 & 0 & 1 \\
\hline & $\begin{array}{l}\text { Gender (Girls were the control } \\
\text { group) }\end{array}$ & 0.535 & 0.499 & 0 & 1 \\
\hline & \multicolumn{5}{|c|}{$\begin{array}{l}\text { Urban and rural categories schools belong to } \\
\text { (Rural schools were the control group) }\end{array}$} \\
\hline & City & 0.648 & 0.478 & 0 & 1 \\
\hline & Country town & 0.296 & 0.456 & 0 & 1 \\
\hline & \multicolumn{5}{|c|}{$\begin{array}{l}\text { Regions schools belong to } \\
\text { (Northern Jiangsu were the control group) }\end{array}$} \\
\hline & Central Jiangsu & 0.159 & 0.366 & 0 & 1 \\
\hline & Southern Jiangsu & 0.498 & 0.5 & 0 & 1 \\
\hline & \multicolumn{5}{|c|}{$\begin{array}{l}\text { The type of school } \\
\text { (Private schools were the control group) }\end{array}$} \\
\hline & Public school & 0.847 & 0.36 & 0 & 1 \\
\hline
\end{tabular}

Note: Due to this research is a different branch of the same project, there is some data overlap. Most of the data in this table are basically consistent with the data of the project team's previous research paper (Yao, et al., 2019). The slight difference is the difference in sample size.

Table 3. Regression Test.

(1) (2)

(3)

(4)

(5)

\begin{tabular}{llllll}
\hline White test & $1054.49^{\star \star \star}$ & $1133.30^{\star \star \star}$ & $1145.49^{\star \star \star}$ & $1367.38^{\star \star \star}$ & $1478.46^{\star \star *}$ \\
\hline Maximum VIF & 4.47 & 4.47 & 4.51 & 4.51 & 4.51 \\
\hline
\end{tabular}

Note: ${ }^{* * *},{ }^{* \star}$, and ${ }^{*}$ represent significance levels of $1 \%, 5 \%$ and $10 \%$, respectively. 


\section{Table 4. Effect of Breakfast and Extracurricular Tutoring on Ele- mentary Students' Academic Performance.}
(1)
(2)
(3)
(4)
(5)

\begin{tabular}{|c|c|c|c|c|c|}
\hline \multirow[t]{2}{*}{ Eat breakfast } & \multicolumn{3}{|l|}{$29.693^{* \star \star}$} & \multicolumn{2}{|l|}{$30.707^{\star \star *}$} \\
\hline & $(26.156)$ & & & $(27.100)$ & \\
\hline \multirow[t]{2}{*}{ Breakfast frequency } & & $13.854^{\star * *}$ & & & $14.150^{\star \star \star}$ \\
\hline & & $(31.436)$ & & & (32.141) \\
\hline \multirow{2}{*}{$\begin{array}{l}\text { Time of extracurricular } \\
\text { tutoring }\end{array}$} & & & $4.514^{\star * *}$ & $4.924^{\star \star *}$ & $4.890^{* \star *}$ \\
\hline & & & $(15.473)$ & $(17.003)$ & $(16.952)$ \\
\hline \multirow{2}{*}{$\begin{array}{l}\text { Socioeconomic status } \\
\text { index }\end{array}$} & $0.580^{* * *}$ & $0.577^{\star \star \star}$ & $0.553^{* * *}$ & $0.506^{\star \star *}$ & $0.504^{* * *}$ \\
\hline & (33.179) & (33.137) & $(30.526)$ & $(28.072)$ & (28.059) \\
\hline \multirow[t]{2}{*}{ Only child } & $19.574^{\star \star \star}$ & $19.357^{\star * *}$ & $18.634^{\star * *}$ & $18.445^{\star \star \star}$ & $18.227^{\star \star \star}$ \\
\hline & $(27.611)$ & $(27.405)$ & $(25.974)$ & $(25.920)$ & $(25.706)$ \\
\hline \multirow[t]{2}{*}{ Gender } & $-6.405^{\star \star \star}$ & $-6.254^{\star \star *}$ & $-6.901^{* * *}$ & $-6.492^{\star \star \star}$ & $-6.345^{\star \star \star}$ \\
\hline & $(-9.490)$ & $(-9.301)$ & $(-10.157)$ & $(-9.629)$ & $(-9.446)$ \\
\hline \multirow[t]{2}{*}{ City } & $8.394^{* * *}$ & $7.949^{\star \star \star}$ & $6.265^{\star * *}$ & $5.949^{\star \star \star}$ & $5.517^{\star \star \star}$ \\
\hline & $(5.094)$ & $(4.837)$ & (3.746) & (3.581) & (3.335) \\
\hline \multirow[t]{2}{*}{ Country town } & $-5.507^{\star \star *}$ & $-5.763^{\star \star \star}$ & $-5.881^{\star \star \star}$ & $-5.972^{\star \star *}$ & $-6.225^{\star \star \star}$ \\
\hline & $(-3.235)$ & $(-3.395)$ & $(-3.421)$ & $(-3.497)$ & $(-3.661)$ \\
\hline \multirow[t]{2}{*}{ Central Jiangsu } & $24.699^{\star \star *}$ & $24.465^{\star \star *}$ & $25.168^{* * *}$ & $24.126^{\star \star \star}$ & $23.908^{\star \star \star}$ \\
\hline & $(18.929)$ & $(18.824)$ & $(19.139)$ & $(18.464)$ & (18.365) \\
\hline \multirow[t]{2}{*}{ Southern Jiangsu } & $7.287^{\star \star \star}$ & $7.051^{\star * *}$ & $7.684^{\star \star *}$ & $6.686^{* \star *}$ & $6.450^{\star \star \star}$ \\
\hline & $(8.058)$ & $(7.820)$ & $(8.426)$ & $(7.383)$ & $(7.147)$ \\
\hline \multirow[t]{2}{*}{ Type of school } & $-4.053^{* * *}$ & $-4.123^{\star \star \star}$ & $-3.613^{* \star *}$ & $-3.844^{\star * *}$ & $-3.894^{* * *}$ \\
\hline & $(-2.944)$ & $(-3.006)$ & $(-2.631)$ & $(-2.799)$ & $(-2.850)$ \\
\hline \multirow[t]{2}{*}{ Constant term } & $450.820^{* * *}$ & $384.434^{* * *}$ & $470.511^{* * *}$ & $445.863^{* * *}$ & $378.384^{* * *}$ \\
\hline & $(189.068)$ & $(106.371)$ & $(211.027)$ & $(185.639)$ & $(104.360)$ \\
\hline Number of samples & 50,516 & 50,516 & 50,214 & 50,214 & 50,214 \\
\hline Adjusted $\mathrm{R}^{2}$ & 0.092 & 0.098 & 0.085 & 0.099 & 0.104 \\
\hline $\mathrm{F}$ & 571.845 & 608.147 & 522.083 & 549.814 & 582.295 \\
\hline
\end{tabular}

Note: The value of $t$ in parentheses is $S D$; ***, **, and * represent significance levels of $1 \%$, $5 \%$ and $10 \%$, respectively. Data in columns 1,2 are basically consistent with the data of the project team's previous research paper (Yao, et al., 2019), The slight difference is the difference in sample size and School types (public school, private school) were added to the control variables in this study. 
Table 5. Effect of Breakfast and Extracurricular Tutoring on Middle Students' Academic Performance.
(1)
(2)
(3)
(4)
(5)

\begin{tabular}{|c|c|c|c|c|c|}
\hline \multirow{2}{*}{ Eat breakfast } & \multicolumn{3}{|l|}{$30.528^{* * *}$} & \multicolumn{2}{|l|}{$30.988^{* * *}$} \\
\hline & $(48.511)$ & & & $(49.578)$ & \\
\hline \multirow{2}{*}{ Breakfast frequency } & & $12.037^{* * *}$ & & & $12.169^{* * *}$ \\
\hline & & $(53.712)$ & & & $(54.797)$ \\
\hline \multirow{2}{*}{$\begin{array}{l}\text { Time of extracurricular } \\
\text { tutoring }\end{array}$} & & & $6.082^{\star * *}$ & $6.532^{\star * *}$ & $6.564^{* \star *}$ \\
\hline & & & $(26.964)$ & $(29.315)$ & $(29.562)$ \\
\hline \multirow{2}{*}{$\begin{array}{l}\text { Socioeconomic status } \\
\text { index }\end{array}$} & $0.844^{* * *}$ & $0.850^{* * *}$ & $0.790^{* * *}$ & $0.723^{\star * *}$ & $0.730^{* * *}$ \\
\hline & $(52.185)$ & $(52.787)$ & $(47.175)$ & $(43.694)$ & $(44.256)$ \\
\hline \multirow{2}{*}{ Only child } & $9.222^{\star * *}$ & $9.066^{\star \star *}$ & $9.070^{* * *}$ & $7.759^{\star \star *}$ & $7.576^{\star \star \star}$ \\
\hline & $(15.230)$ & $(15.021)$ & $(14.815)$ & $(12.845)$ & $(12.586)$ \\
\hline \multirow{2}{*}{ Gender } & $-18.589^{* * *}$ & $-18.083^{* * *}$ & $-16.574^{\star * *}$ & $-17.614^{\star \star *}$ & $-17.075^{\star \star \star}$ \\
\hline & $(-32.985)$ & $(-32.213)$ & $(-29.146)$ & $(-31.410)$ & $(-30.576)$ \\
\hline \multirow{2}{*}{ City } & $15.923^{* * *}$ & $15.707^{* * *}$ & $13.288^{* * *}$ & $13.768^{\star \star \star}$ & $13.535^{\star \star \star}$ \\
\hline & $(12.298)$ & (12.199) & $(10.163)$ & $(10.663)$ & $(10.525)$ \\
\hline \multirow{2}{*}{ Country town } & $9.229^{* * *}$ & $9.006^{* * *}$ & $9.414^{\star * *}$ & $9.739^{* * *}$ & $9.506^{\star * *}$ \\
\hline & $(6.996)$ & $(6.866)$ & $(7.081)$ & $(7.419)$ & $(7.272)$ \\
\hline \multirow{2}{*}{ Central Jiangsu } & $19.145^{\star * *}$ & $19.173^{\star \star *}$ & $19.578^{\star \star *}$ & $18.302^{* * *}$ & $18.325^{\star \star *}$ \\
\hline & $(21.706)$ & $(21.825)$ & $(21.984)$ & $(20.861)$ & $(20.968)$ \\
\hline \multirow{2}{*}{ Southern Jiangsu } & $15.664^{* * *}$ & $15.361^{* * *}$ & $14.094^{* * *}$ & $14.147^{* * *}$ & $13.834^{* \star *}$ \\
\hline & $(23.066)$ & $(22.697)$ & $(20.511)$ & $(20.886)$ & $(20.497)$ \\
\hline \multirow{2}{*}{ The type of school } & $-40.549^{* * *}$ & $-40.575^{\star \star \star}$ & $-42.236^{\star * *}$ & $-40.687^{* * *}$ & $-40.748^{\star * *}$ \\
\hline & $(-52.251)$ & $(-52.396)$ & $(-54.092)$ & $(-52.632)$ & $(-52.902)$ \\
\hline \multirow{2}{*}{ Constant term } & $461.302^{* * *}$ & $406.534^{* * *}$ & $475.805^{\star * *}$ & $455.616^{* * *}$ & $400.327^{* * *}$ \\
\hline & $(282.142)$ & $(193.587)$ & $(295.861)$ & $(277.823)$ & $(190.665)$ \\
\hline Number of samples & 83,505 & 83,505 & 83,170 & 83,170 & 83,170 \\
\hline Adjusted $\mathrm{R}^{2}$ & 0.143 & 0.148 & 0.126 & 0.151 & 0.156 \\
\hline $\mathrm{F}$ & $1,543.740$ & $1,608.537$ & $1,333.657$ & $1,479.943$ & $1,541.276$ \\
\hline
\end{tabular}

Note: The value of $t$ in parentheses is $S D ;{ }^{* *}, * *$, and * represent significance levels of $1 \%$, $5 \%$ and $10 \%$, respectively. Data in columns 1,2 are basically consistent with the data of the project team's previous research paper (Yao, et al., 2019). The slight difference is the difference in sample size and School types (public school, private school) were added to the control variables in this study. 
teristics, breakfast and extracurricular tutoring were positively correlated with students' academic performance at a significance level of $1 \%$. Specifically, it can be found from the results of models (1) and (4) that students eating breakfast every day had significantly higher scores about 30 points than those who ate breakfast irregularly. According to the results of models (2) and (5), students' scores would be improved by about 12 points for every extra day of breakfast in a week. Besides, extracurricular tutoring also had a significantly positive influence on student' academic performance according to the results of models (3), (4) and (5).

In addition, in middle schools, the students' family background had a significant positive effect on students' performance (see Table 5) suggesting that students with a better family background tended to gain higher scores. From the perspective of individual characteristic, male students scored about 16-18 points lower than female students, having siblings scored about 7-9 points lower than students who were the only child in their families. In terms of school characteristics, the scores of students in urban, counties and towns were higher than the scores of the students from rural areas. The students in the Central and Southern parts of Jiangsu Province had a better academic performance than their peers did in the North. Moreover, the scores of public school students were lower than their private school peers about 40 points.

\section{Which is More Effective: Breakfast or Extracurricular Tutor- ing - The Analysis Based on Shapley Value}

The estimated coefficients of the aforementioned regression equation only showed the influence of breakfast and extracurricular tutoring on student' academic performance, but it was unclear that to what extent the relevant explanatory variables would contribute to academic performance (difference in students' performance), and which of them could have a more significant influence on students' academic performance. To get further observation, Shapley Value Decomposition method was used to analyze the factors that lead to differences in students' academic performance and to compare the relative contribution rate each factor.

The idea of Shapley Value Decomposition comes from Shorrocks, (Shorrocks, 1982) and the basic principle of which was to estimate the relative significance of independent variables through examining the contribution rate of different independent variables to the difference of dependent variables. Taking breakfast frequency as an instance, its influence on students' academic performance mainly stems from two aspects: (1) The correlation coefficient between breakfast frequency and students' academic performance. When the other factors remain unchanged, the larger the coefficient is, the greater the degree of explanation for the difference in students' academic performance will be. (2) The distribution of breakfast frequency. The more uneven the distribution is, the greater its contribution to the difference in students' academic performance will be.

Table 6 shows the results of Shapley Value Decomposition method in elementary schools. The contribution rate of family socioeconomic status to the difference in students' academic performance was $31.96 \%$. According to the decomposition result of 
Table 6. The Decomposed Contribution of Variables to Elementary Students' Academic Performance.

\begin{tabular}{llllll}
\hline & $\mathbf{( 1 )}$ & $\mathbf{( 2 )}$ & $\mathbf{( 3 )}$ & $\mathbf{( 4 )}$ & $\mathbf{( 5 )}$ \\
\hline Eat breakfast & $16.99 \%$ & & & $16.37 \%$ & \\
\hline Breakfast frequency & & $23.11 \%$ & & & $22.01 \%$ \\
\hline Tutoring & & & $13.33 \%$ & $11.96 \%$ & $11.25 \%$ \\
\hline $\begin{array}{llllll}\text { Family socioeconomic } \\
\text { background }\end{array}$ & $31.96 \%$ & $30.07 \%$ & $32.16 \%$ & $26.18 \%$ & $24.75 \%$ \\
\hline Only child & $23.27 \%$ & $21.76 \%$ & $23.73 \%$ & $20.27 \%$ & $19.04 \%$ \\
\hline Gender & $1.99 \%$ & $1.84 \%$ & $2.28 \%$ & $1.86 \%$ & $1.73 \%$ \\
\hline City & $9.24 \%$ & $8.64 \%$ & $9.05 \%$ & $7.69 \%$ & $7.23 \%$ \\
\hline Country town & $6.31 \%$ & $5.95 \%$ & $6.31 \%$ & $5.39 \%$ & $5.10 \%$ \\
\hline Central Jiangsu & $7.12 \%$ & $6.67 \%$ & $7.82 \%$ & $6.53 \%$ & $6.14 \%$ \\
\hline Southern Jiangsu & $3.39 \%$ & $3.15 \%$ & $3.49 \%$ & $2.82 \%$ & $2.63 \%$ \\
\hline Type of school & $0.18 \%$ & $0.17 \%$ & $0.16 \%$ & $0.14 \%$ & $0.14 \%$ \\
\hline
\end{tabular}

model (1), only-one child and breakfast accounted for $23.27 \%$ and $16.99 \%$ of the difference in student performance, respectively. Characteristics such as gender, school location and type explained about $28 \%$ of the difference in students' academic performance. The decomposition result of model (2) was similar to that of model (1). The contribution rate of family socioeconomic status to the difference in students' academic performance was the largest with $30.07 \%$. The breakfast frequency and the only-one child accounted for $23.11 \%$ and $21.76 \%$ of the difference in students' academic performance, respectively. In model (3), the top three explanatory contributors for the difference in students' academic performance were family socioeconomic status, only-one child, and tutoring time, accounting for $32.16 \%, 23.73 \%$, and $13.33 \%$, respectively. On the basis of models (1) and (2), after taking the tutoring time into model, we found that the contribution rate of family socioeconomic status on students' academic performance differences was still the largest (26.18\% and $24.75 \%$, respectively), the explanatory rate of eating or not eating breakfast and the breakfast frequency for students' academic performance were higher than the tutoring time. The only-one child variable explained for about $20 \%$ degree of students' academic performance difference.

Table 7 is the results of Shapley Value Decomposition method in middle schools. From the decomposition results of model (1), it can be found that the contributory rate of family socioeconomic status to the difference in students' academic performance was $30.31 \%$. The type of school and whether they ate breakfast accounted for $20.82 \%$ and $20.06 \%$ of the difference in students' academic performance, respectively and student characteristics and school area accounted for about $29 \%$ of the interpretable 
Table 7. The Decomposed Contribution of Variables to Middle Students' Academic Performance.

(1)

\begin{tabular}{lccccc}
\hline Eat breakfast & $20.06 \%$ & & & $19.28 \%$ & \\
\hline Breakfast frequency & & $23.27 \%$ & & & $22.30 \%$ \\
\hline Tutoring & & & $13.92 \%$ & $11.98 \%$ & $11.60 \%$ \\
\hline $\begin{array}{l}\text { Family socioeconomic } \\
\text { background }\end{array}$ & $30.31 \%$ & $29.46 \%$ & $31.82 \%$ & $24.88 \%$ & $24.20 \%$ \\
\hline Only child & $5.69 \%$ & $5.47 \%$ & $6.10 \%$ & $4.70 \%$ & $4.52 \%$ \\
\hline Gender & $7.39 \%$ & $6.91 \%$ & $7.40 \%$ & $6.59 \%$ & $6.17 \%$ \\
\hline City & $4.80 \%$ & $4.62 \%$ & $4.63 \%$ & $3.87 \%$ & $3.73 \%$ \\
\hline Country town & $2.27 \%$ & $2.19 \%$ & $2.23 \%$ & $1.86 \%$ & $1.79 \%$ \\
\hline Central Jiangsu & $2.32 \%$ & $2.25 \%$ & $2.70 \%$ & $2.05 \%$ & $1.99 \%$ \\
\hline Southern Jiangsu & $4.64 \%$ & $4.39 \%$ & $4.49 \%$ & $3.78 \%$ & $3.58 \%$ \\
\hline Type of school & $20.82 \%$ & $20.17 \%$ & $24.69 \%$ & $19.77 \%$ & $19.17 \%$ \\
\hline
\end{tabular}

variation. The decomposition result of model (2) shows that the contribution rate of socioeconomic status of family to the difference in students' academic performance was the largest with $29.46 \%$, breakfast frequency to the difference in students' performance was $23.27 \%$, and school type to the difference in students' performance was $20.17 \%$. In model (3), the top three explanatory variables for the difference in students' academic performance were family socioeconomic status, type of school and tutoring time, accounting for $31.82 \%, 24.69 \%$ and $13.92 \%$, respectively. According to models (4) and (5), it was found that the contribution rate of socioeconomic status of family to the difference in student' performance was still the largest ( $24.88 \%$ and $24.20 \%$, respectively). The contribution rate of breakfast and breakfast frequency to the difference in students' academic performance was higher than that of the tutoring. The contribution rates of school type to the difference in students' academic performance was $19.77 \%$.

To conclude, based on the result of Shapely Value Decomposition, we found that to both elementary school and middle school students, family socioeconomic status had the greatest impact on their academic performance, indicating that family background is still one of the most important factors affecting education output. Secondly, elementary school students' breakfast variable accounted for 16\%-23\% of the difference in scores, while extracurricular tutoring explained $11 \%-13 \%$ of the difference in scores. In middle schools, $19 \%-23 \%$ of the differences in students' academic performance were resulted from breakfast, and $11 \%-14 \%$ were resulted from extracurricular tutoring. Thus, we concluded that breakfast and extracurricular tutoring are important contributors for the differences in students' academic performance. However, the influ- 
ence of breakfast on students' academic performance is greater than that of extracurricular tutoring.

In addition, for elementary schools, the contribution rate of only-one child variable to the differences of students' academic performance was relatively large, whereas in middle schools, this effect was not that obvious. Secondly, compared with other variables, the types of the elementary schools had the least influence on the difference in students' academic performance. For middle schools, the contribution rate of school type to the differences in students' academic performance was relatively larger, which reached about $19 \%$. Therefore, there may be differences between elementary and middle schools in the mechanisms that affect students' academic performance.

\section{Discussion: Explore More Effective Ways of Family Educa- tion}

The purpose of this study was to analyze and compare the impact of breakfast and extracurricular tutoring on students' academic performance, so as to offer suggestions to which kind of family education was more effective in improving the students' academic achievements.

It was found that in the basic education stage (Year-1 to Year-9), when the individual, family and school characteristics were controlled, both breakfast and extracurricular tutoring had a significant positive impact on students' academic performance, which is consistent with the findings from others (Fang, 2014; Fang, 2018; Peng, 2008). Meanwhile, previous studies indicated that the socioeconomic status of families would influence the expenditure of extracurricular tutoring, and high-income families might invest more in extracurricular tutoring (Le \& Du, 2018; Qu \& Xue, 2015), so for children from low-resource families, the high cost of extracurricular tutoring may put them at a disadvantage. However, our study found that extracurricular tutoring is not the only effective way to improve children's performance. Breakfast is also conducive to the improvement of students' academic performance, and the cost of such an intervention is far lower than that of extracurricular tutoring. For example, through a randomized controlled experiment, Kleiman-Weiner et al. (2013) studied 2,686 fourth-graders in 70 schools in five poverty-stricken counties in Gansu Province for six months, and found that a chewable vitamin tablet costing only $0.4 \mathrm{CNY}$ per day could significantly improve students' math scores, meaning that paying more attention to breakfast and providing students with a balanced and healthy supply of nutrients may result in better academic performance.

Possible explanations for the significant influence of breakfast on students' academic performance may attribute to the following three reasons. First of all, nutrition is guaranteed, breakfast provides the nutrition needed by the body and ensures students' energy and condition in learning activities in the morning. Second, breakfast represents some kind of lifestyle, and students with self-discipline are more likely to be successful. Third, insisting on making breakfast for children also means a positive attitude of parents' educational participation, which will also affect students' academic 
performance. Li \& Qiu (2016) found that parents' participation in children's education had a positive impact on children's academic performance. Li \& He (2019) also found that the time invested during family education had the greatest impact on students' academic performance in comparison with the extracurricular tutoring. Breakfast, as a part of family education in the time investment and parental education participation, it obviously has a positive impact on students' academic performance.

Our results also reveal that to prepare their children for fierce academic competitions, parents may not need to increase the academic burdens of their children. Instead, improving students' nutritional status through breakfast and food, improving parentchild relationship through participating in children's education, and creating a good family environment may serve as better options. Besides, both parents and researchers can look for better strategies or combination of strategies to promote child development through low-input but high-productivity family interventions.

The lack of data on breakfast contents in the questionnaire is a limitation of this study, so we are unable to explore the effect of the breakfast quality or its ingredient types on students' academic performance. Meanwhile, our study did not subdivide the extracurricular tutoring types, so it remains unclear if the tutoring types may impact the students' academic outcomes. Further studies are needed to explored these questions and expanding further understanding on these topics.

\section{Conclusion and Suggestions}

Eating breakfast and tutoring are two common ways that family education can use to improve students' academic performance. Although studies have explored the relationship between tutoring and students' academic performance, but the relationship between breakfast and academic outcome is less explored, especially with rigorous empirical research. This study used Chinese evidence to analyze this issue. Specifically, based on the monitoring data of basic education academic quality in Jiangsu Province, our study explored the effect of breakfast and extracurricular tutoring on students' academic performance by using multiple linear regression methods. The Shapley Value Decomposition method was adopted to compare the relatively contributory rate of breakfast and extracurricular tutoring to students' academic performance.

Through the empirical study, we found that first of all, breakfast and extracurricular tutoring have a significant positive impact on elementary and middle school students' academic performance. Besides, students eating breakfast every day had a significantly higher score than those who ate breakfast irregularly. For each additional day of eating breakfast for a week, the student's score would be increased by 12-14 points. Taking part in extracurricular tutoring also helped students to improve their scores, but the explanatory power of the breakfast in students' academic performance was greater than that of extracurricular tutoring.

Based on these findings, we strongly suggest that parents should pay more attention to the role of breakfast and be rational to extracurricular tutoring. As the elementary education stage is a crucial period for students' physical and mental develop- 
ment, it is crucial to ensure that children can get sufficient nutrient supply. In addition to providing breakfast for children, parents should also try to make children cultivate their healthy habits of eating breakfast regularly and ensure adequate rest to avoid sleep-deprivation associated missing of breakfast. Meanwhile, our research also shows that extracurricular tutoring is positively related to students' performance, but its impact is not as significant as that of eating breakfast. In combination with some other studies showing that high frequency of tutoring was negatively correlated with the scores (Tang $\& \mathrm{Fu}, 2007)$ suggest that parents should use tutoring rationally. A more efficient and balanced family education strategy should be adopted accordingly with the actual situation of the family and their children.

On the other hand, the government and schools should allocate more resources to promote students' academic progress and reach fair educational outcomes. The results of this study show that extracurricular tutoring can help students to improve their academic performance. However, the cost of extracurricular tutoring is high. In order to minimize the educational inequality brought about by family's different background, the government may consider to provide appropriate resources of extracurricular tutoring to disadvantaged families in the form of preferential or subsidy to maximize the development of those with less resources. At the same time, given the significant role of breakfast in promoting students' performance, the importance of eating breakfast should be popularized by the governments and schools. For the school, they can strengthen students' healthy lifestyle education, and also preach the importance of breakfast and nutritional balance to parents. For the governments, they can increase the welfare subsidies for disadvantaged families and ensure the quality of breakfast they have to leverage the fairness of educational outcomes with limited funding.

\section{References}

Cooper, S. B., Bandelow, S., \& Nevill, M. E. (2011). Breakfast consumption and cognitive function in adolescent schoolchildren. Physiol Behav, 103(5):431-439.

Fang, C. C. (2018). An Empirical Study of the Effects of Breakfast on Students' Achievements. J Shanghai Edu Res, 375(08):15-18.

Fang, C. C., \& Xue, H.P. (2014). An empirical study of the influence of tutoring on students' performance in compulsory education. J Shanghai Edu Res, (12): 5-9.
Frisvold, D. E. (2015). Nutrition and cognitive achievement: An evaluation of the school breakfast program. J Public Econ, (124): 91-104.

Hau, K. T. (2016). Have breakfast rather than wasting money on tutorial. EdData Speaks, No.2. EdDataX Research Centre.

Ho, C. Y., Huang, Y. C., Lo, Y. T. C., Wahlqvist, M. L. , \& Lee, M. S. (2015). Breakfast is associated with the metabolic syndrome and school performance among 
taiwanese children. Research in developmental disabilities, 43-44, 179-188.

Hu, Y. M., Fan, W. F., \& Ding, W. L. (2015). Does shadow education aggravate inequality of educational outcomes? An empirical study on PISA 2012 shanghai data. Peking Univ Edu Rev,13(03):29-46+188.

Kang, Y. W., \& Park, J. H. (2016). Does skipping breakfast and being overweight influence academic achievement among korean adolescents? Osong Public Health Res Perspect, 7(4):220-227.

Kleiman-Weiner, M., Luo, R., Zhang, L., Shi, Y., Medina, A. , \& Rozelle, S. (2013). Eggs versus chewable vitamins: which intervention can increase nutrition and test scores in rural China? Chin Econ Rev, 24:165-176.

Le, Z. Q., \& Du, Y. H. (2018). The influence of family backgrounds on the students' behavior choices of the private tutoring. Res Edu Dev, 38(10), 7-14.

Li, C. L. (2005). Prestige stratification in the contemporary china: Occupational prestige measures and socio-economic index. Soc Stud, (02):74-102+244.

Li, J. L, \& He, R. Z. (2019). Family education, time investment, economic investment and youth development: social capital, cultural capital and the interpretation of shadow education. Chin Youth Res, (08):97-105.

Li, J. L. (2018). The effect of private tutoring on the academic achievement of students from western rural area in china? Fixed effect analysis based on panel data. J Sch Studies, 15(01): 90-98.

Li, J. L., Hu,Y. M., \& Fan, W. F. (2016). Family background, shadow education and student achievement: Based on empirical research of Wisconsin model. Chin Econ Edu Rev,1(01): 70-89.

Li, Z. L., \& Qiu, Z.Q. (2016). Family background and children's academic performance: Evidence from the compulsory education in China. Socio Stud,31 (04): 121-144.

Lien, L. (2007). Is breakfast consumption related to mental distress and academic performance in adolescents? Public

Health Nutri, 10(04):422-428.

Liu, T. X., \& Wang, Q. (2018). Private tutoring and student's educational attainment: Evidence from secondary school in China. China Edu Econ Rev, 3(05):70-94.

Lu, X. Y. (2002). Analysis of the top ten classes in contemporary Chinese society. Stu Pract, (3): 55-63.

Mark, B., \& Liu, J.Y. (2015). Conducting Research into Private Supplementary Tutoring: Methods and Approaches. Peking Univ Edu Rev, 13(03): 2-16.

O'Sullivan, T., Robinson, M., Kendall, G., Miller, M., Jacoby, P., Silburn, S., \& Oddy, W. (2009). A good-quality breakfast is associated with better mental health in adolescence. Public Health Nutr, 12(2):249-258.

Peng, P., \& Zhou, Z.B. (2008). Study on tutoring in urban compulsory education- Based on sample survey of $\mathrm{h}$ district, $\mathrm{Wu}$ han city, Hubei Province. Prim Seco Sch Man (4), 22-25.

Qu, Y., \& Xue, H.P. (2015). Research on private cost of extracurricular tutoring in compulsory education in China. J Shanghai Edu Res, (04):21-26.

Rampersaud, G. C., Pereira, M. A., Girard, B.L., Adams, J. , \& Metzl, J. D. (2005). Breakfast habits, nutritional status, body weight, and academic performance in children and adolescents. J Am Diet Association, 105(5), 743-760.

Sampasa-Kanyinga, H., \& Hamilton, H. A. (2017). Eating breakfast regularly is related to higher school connectedness and academic performance in Canadian middleand high-school students. Public Health, 145: 120-123.

Shorrocks, A. F. (1982). Inequality decomposition by factor components.

Econometrica, 50 (1):193-211.

Snilstveit, B., Stevenson, J., Phillips, D., Vojtkova, M., Gallagher, E., Schmidt, T., Jobse, H., Geelen, M., Pastorello, M., \& Eyers, J. (2015). Interventions for improving learning outcomes and access to education in low- and middle- income countries: a systematic review, 3ie Systematic 
Review 24. London: International Initiative for Impact Evaluation (3ie).69-97.

Sun, J.,\&Yin, J. S. (1994). The impact of breakfast quality on classroom teaching effectiveness. Chin J Sch Health, (06): 447-447.

Sun, L. X., \& Tang, J. J. (2019). The effectiveness of private tutoring: an estimation based on China education panel survey. Peking Univ Edu Rev, 17(01): 123$141+191$.

Tang, L. C., \& Fu, L. J. (2007). An empirical study on the relationship between academic burden and academic achievement. J Shanghai Edu Res, (12): 32-36.

Wang, J. J. (2005). Family education and school education: a vicious circle that cannot be achieved. J Sch Stu Res, (10): 8-9.

Widenhorn-Müller, K., Hille, K., Klenk, J.,\&Weiland, U.(2008).Influence of having breakfast on cognitive performance and mood in 13- to 20-year-old high school students: Results of a crossover trial. pediatrics, 122(2): 279-284.

Wooldridge,J.M. (2009).Introductory econometrics: A modern approach (4th edition). South-Western Cengage Learn.

Xu, H. Q., Hu, X. Q., Zhang, Q., Li, L., Zhang, F., \& Pan, H., Ma, G.S. (2014). Analysis of the correlation between breakfast frequency and students' scores in poor areas. Chin J Sch Health, 35(12):1788-1790.

Xue, H. P. (2016). Extracurricular tutoring, student achievements and social reproduction. Edu Econ, (02):32-43.
Xue, H. P. (2017). Family capital and education acquisition: A Perspective of shadow education. Edu Sci Res, (02):31-41+48.

Xue, H. P., \& Ding, X. H. (2009). A study on additional instruction for students in cities and towns in China. Edu Res, (01): 41-48.

Xue, H. P., Wang, D., \& Wu, X. W. (2014). The impact of private tutoring on leftbehind students' academic achievements in Chinese compulsory education. Peking Unive Edu Rev, 12(3):50-62.

Yang, Q. L. (2004). On the necessity of "tutorship" reform and its selection strategy - re-discussion on the issue of "tutorship" in practice. Cont Edu Sci, (21):8-11.

Yao, J. J. (2008). On the comprehensive measuring of educational balancing development: Principles and methods. Edu Sci, 03: 5-8.

Yao, J. J., Liu, Y. L., \& Zhou, S. K. (2019). Effect of eating breakfast on cognitive development of elementary and middle school students: An empirical study using large-scale provincial survey data. Med Sci Monit, 25: 8843-8853.

Zhang, Y. (2013). Does private tutoring improve students' national college entrance exam performance? A case study from Jinan, China. Econ Edu Rev, 32:1-28.

Zhejiang News. (2017). Students who regularly eat breakfast every day have generally good academic performance [EB/OL].http://zjnews.zjol.com.cn/zjnews /hznews/201705/t20170523_4029557.sht $\mathrm{ml}$.

Received: 04 January 2020

Revised: 10 January 2020

Accepted: 03 February 2020 